\title{
Failure Dependence of High-Rise Frame Shear-Wall Structures under Frequently Occurred Earthquakes and Its Application
}

\author{
Junfeng Zhu ${ }^{1}$, Yifan $\mathrm{Li}^{1} \&$ Qun Mei ${ }^{1}$ \\ ${ }^{1}$ College of Planning and Architectural Engineering, Henan University of Science and Technology, Luoyang, \\ China \\ Correspondence: Junfeng Zhu, College of Planning and Architectural Engineering, Henan University of Science \\ and Technology, No. 263, Kaiyuan Road, Luolong District, Luoyang, 471023, China. E-mail: \\ junfeng-zhu@163.com
}

Received: October 29, 2012

Accepted: November 15, 2012 Online Published: November 30, 2012

doi:10.5539/mer.v2n2p120

URL: http://dx.doi.org/10.5539/mer.v2n2p120

\begin{abstract}
In order to simplify calculation of structural system reliability, it is necessary to study failure dependence of structure. In this paper, failure dependence of high-rise frame shear-wall structure is studied based on interstory deformation under frequently occurred earthquakes. From the analytical results, some useful laws of failure dependence are obtained. The failure between the layers of high-rise frame shear-wall structure is neither fully independent, nor entirely relevant under frequently occurred earthquakes. The failure relevant number accounts for half the total number of high-rise frame shear-wall structure. The failure relevant layers concentrate on the upper part of high-rise frame shear-wall structure. Structural system reliability is calculated base on failure dependence. It is feasible to calculate structural system reliability considering the failure of interstory deformation as main failure modes, and the calculation of structural system reliability can be greatly simplified.
\end{abstract}

Keywords: failure dependence, system reliability, frame shear-wall structure, frequently occurred earthquakes

\section{Introduction}

Conceptually speaking, structural system reliability is an important index to measure the overall performance of building structures. Through the efforts of many researchers, structural system reliability theory has made great progress in areas such as electronics, machinery etc, which has begun to be used in engineering practice. But in the field of civil engineering, due to the influence of many factors, it is difficult to apply system reliability to civil engineering. Up to now, structural design only considers reliability of a member or a section, and doesn't take structural system reliability into account. Application of structural reliability is only at the level of structural members, and partial factors are used to take into account uncertainty.

It is well known that there are multiple failure modes for a structure under certain failure criterion. Structural failure modes increase by series level with an increase in structures and redundant system components. Reliability analysis of structural system is the major difficulty facing structural failure modes, but also there is a correlation among various failure modes. It is impossible to search all failure modes for system reliability analysis of complex structure. Theoretical analysis has shown that only a small number of failure modes play a major role among many failure modes in structural system reliability, other failure modes can be ignored. Structural system reliability can be indicated by failure probability of a few dominant failure modes (Ou \& Hou, 2001).

In recent years, performance-based seismic design has become hot spots. Performance-based seismic design should be based on structural reliability theory, more precisely based on structural system reliability theory and its application in engineering structures (Moses, 1990). It is known that structure damage is primarily due to interstory deformation caused by excessive from practical experience of earthquakes. For high-rise reinforced concrete structure, failure of interstory deformation is the main failure mode under earthquakes (Cheng \& $\mathrm{Li}$, 2000, 2001, 2002).

\section{Method}

\subsection{Load Information}

In this paper, load includes vertical load and horizontal load. Vertical load is mainly structural weight, which is a 
random variable and follows normal distribution. Horizontal load simulates horizontal earthquakes, which is also a random variable and obeys extreme-I distribution.

\subsection{Structural Failure Criterion}

It is necessary to establish the limit state equation in order to analyze seismic reliability of structure. The limit state equation is based on structural failure criteria. At present, there are some criteria for structural failure: (1) failure criterion of strength, (2) failure criterion of deformation, (3) failure criterion of energy, (4) failure criterion of deformation and energy. Failure criterion of deformation is not only simple, but also can reflect structural performance under earthquakes. So it has been widely applied in practical engineering. According to the overall objectives of the seismic design of frame shear-wall structure under frequently occurred earthquakes, the limit state equation is defined based on interstory drift as follows:

$$
Z=[\Delta u]-\Delta u \begin{cases}>0 & \text { reliable state } \\ =0 & \text { limit state } \\ <0 & \text { failure state }\end{cases}
$$

Where $[\Delta u]$ is a limit value of interstory drift of frame shear-wall structure under frequently occurred earthquakes, $[\Delta u]=\frac{1}{800} h \cdot h$ is a floor height. $\Delta u$ is an interstory drift.

\subsection{Judgment of Failure Dependence}

Interstory drift of each floor can be got after reliability analysis of frame shear-wall structure has been finished. Failure information can be known when interstory drift of each floor is compared with its limit value. When a floor is reliable, its information is " 1 ". When the floor is failure, its information is " 0 ". According to probability theory, failure correlation coefficients can be calculated.

According to probabilistic networks technology (abbreviation for PNET), when failure correlation coefficient between two layers is larger than 0.7 , it can be considered that failure of these two layers is statistically correlative, or else failure of these two layers is statistically independent (Ang \& Tang, 1984; Ang \& Ma, 1981).

\section{Example}

In this paper, three-span-twelve-story frame shear-wall structure and three-span-eighteen-story frame shear-wall structure are analyzed. Seismic precautionary intensity of two structures is eight degree. Concrete strength class of frame column is $\mathrm{C}_{30}$, and that of frame beam is $\mathrm{C}_{25}$. Longitudinal steel bars use $\mathrm{HRB}_{335}$, and stirrups use $\mathrm{HPB}_{300}$. Floor height is $3.0 \mathrm{~m}$. Sections of beams are $0.25 \mathrm{~m} \times 0.6 \mathrm{~m}$, and those of columns are $0.5 \mathrm{~m} \times 0.5 \mathrm{~m}$. Thickness of shearwall is $0.2 \mathrm{~m}$. Plane layout of frame-shearwall structure is shown in Figure 1. Finite element models of twelve-story and eighteen-story frame shear-wall structures are shown in Figure 2 and Figure 3 respectively.

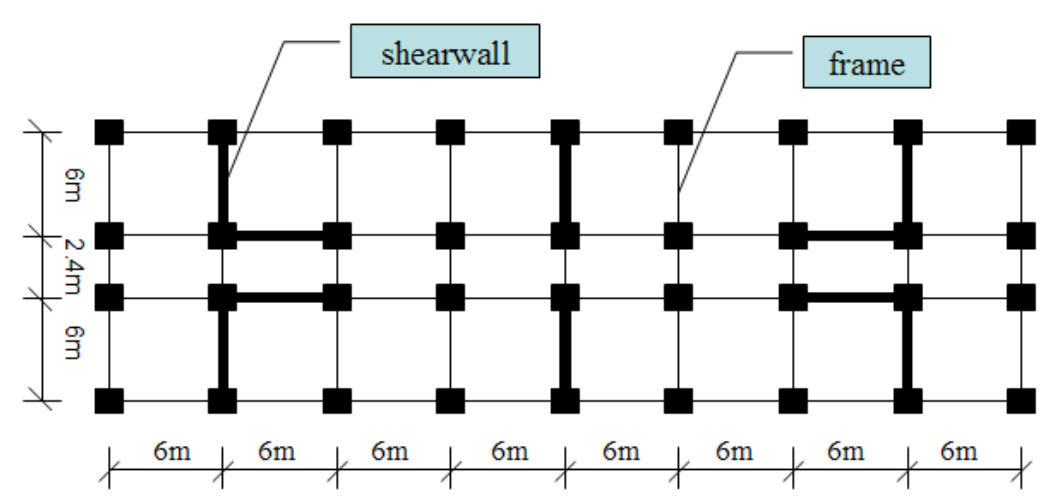

Figure 1. Plane layout of frame shear-wall structure 


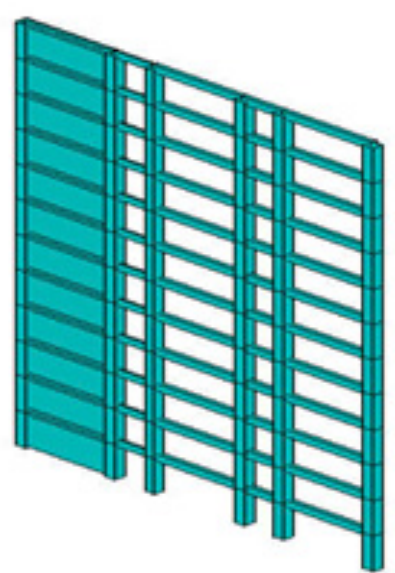

Figure 2. Finite element model of 12-story structure

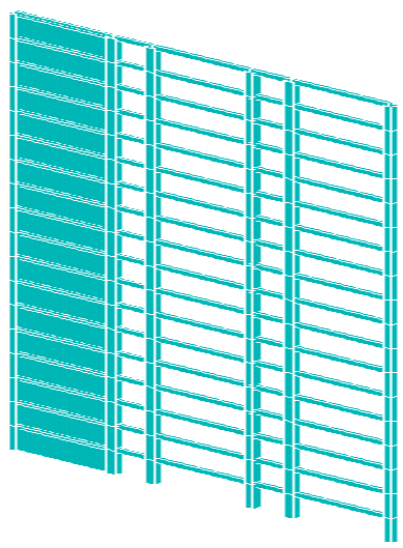

Figure 3. Finite element model of 18-story structure

In this paper, it is assumed that the slab in the in-plane stiffness is infinite. Lateral component in their out-of-plane stiffness is zero. All shear walls are combined into a composite shear wall. All frames are combined into a composite frame. The hinge joint is used to connect the composite shear wall with the composite frame.

\subsection{Failure Correlation Coefficients}

In this paper, failure correlation coefficients are calculated according to probability theory. Failure correlation coefficients of two examples are shown in Table 1 and Table 2. RI is the abbreviation of related interstory and $\mathrm{CC}$ is the abbreviation of correlation coefficients in Table 1 and Table 2.

Table 1. Failure correlation coefficients of twelve-story frame shear-wall structure

\begin{tabular}{ccccccccccccc}
\hline \multicolumn{2}{c}{ Number one } & \multicolumn{2}{c}{ Number two } & \multicolumn{2}{c}{ Number three } & \multicolumn{2}{c}{ Number four } & \multicolumn{2}{c}{ Number five } & \multicolumn{2}{c}{ Number six } \\
\hline RI & CC & RI & CC & RI & CC & RI & CC & RI & CC & RI & CC \\
\hline $4-5$ & 0.4585 & $4-11$ & 0.1313 & $5-10$ & 0.2882 & $6-10$ & 0.5426 & $7-11$ & 0.7471 & $9-10$ & 0.9510 \\
$4-6$ & 0.2346 & $4-12$ & 0.1325 & $5-11$ & 0.2863 & $6-11$ & 0.5389 & $7-12$ & 0.7540 & $9-11$ & 0.9445 \\
$4-7$ & 0.1757 & $5-6$ & 0.5312 & $5-12$ & 0.2889 & $6-12$ & 0.5438 & $8-9$ & 0.9136 & $9-12$ & 0.9531 \\
$4-8$ & 0.1521 & $5-7$ & 0.3832 & $6-7$ & 0.7213 & $7-8$ & 0.8659 & $8-10$ & 0.8688 & $10-11$ & 0.9932 \\
$4-9$ & 0.1390 & $5-8$ & 0.3318 & $6-8$ & 0.6245 & $7-9$ & 0.7910 & $8-11$ & 0.8629 & $10-12$ & 0.9977 \\
$4-10$ & 0.1322 & $5-9$ & 0.3031 & $6-9$ & 0.5706 & $7-10$ & 0.7522 & $8-12$ & 0.8708 & $11-12$ & 0.9909 \\
\hline
\end{tabular}


Table 2. Failure correlation coefficients of eighteen-story frame shear-wall structure

\begin{tabular}{cccccccccccc}
\hline \multicolumn{2}{c}{ Number one } & \multicolumn{2}{c}{ Number two } & \multicolumn{3}{c}{ Number three } & \multicolumn{2}{c}{ Number four } & \multicolumn{2}{c}{ Number five } & \multicolumn{2}{c}{ Number six } \\
\hline RI & CC & RI & CC & RI & CC & RI & CC & RI & CC & RI & CC \\
\hline $6-7$ & 0.6028 & $7-9$ & 0.4041 & $8-12$ & 0.3993 & $9-16$ & 0.5389 & $11-14$ & 0.8331 & $13-16$ & 0.9082 \\
$6-8$ & 0.3845 & $7-10$ & 0.3221 & $8-13$ & 0.3759 & $9-17$ & 0.5401 & $11-15$ & 0.8078 & $13-17$ & 0.9103 \\
$6-9$ & 0.2436 & $7-11$ & 0.2726 & $8-14$ & 0.3561 & $9-18$ & 0.5438 & $11-16$ & 0.7987 & $13-18$ & 0.9165 \\
$6-10$ & 0.1942 & $7-12$ & 0.2546 & $8-15$ & 0.3453 & $10-11$ & 0.8463 & $11-17$ & 0.8005 & $14-15$ & 0.9696 \\
$6-11$ & 0.1643 & $7-13$ & 0.2397 & $8-16$ & 0.3414 & $10-12$ & 0.7904 & $11-18$ & 0.8060 & $14-16$ & 0.9587 \\
$6-12$ & 0.1535 & $7-14$ & 0.2271 & $8-17$ & 0.3422 & $10-13$ & 0.7442 & $12-13$ & 0.9415 & $14-17$ & 0.9608 \\
$6-13$ & 0.1445 & $7-15$ & 0.2202 & $8-18$ & 0.3445 & $10-14$ & 0.7051 & $12-14$ & 0.8920 & $14-18$ & 0.9674 \\
$6-14$ & 0.1369 & $7-16$ & 0.2177 & $9-10$ & 0.7973 & $10-15$ & 0.6837 & $12-15$ & 0.8649 & $15-16$ & 0.9887 \\
$6-15$ & 0.1328 & $7-17$ & 0.2182 & $9-11$ & 0.6747 & $10-16$ & 0.6759 & $12-16$ & 0.8551 & $15-17$ & 0.9909 \\
$6-16$ & 0.1313 & $7-18$ & 0.2197 & $9-12$ & 0.6302 & $10-17$ & 0.6774 & $12-17$ & 0.8570 & $15-18$ & 0.9977 \\
$6-17$ & 0.1316 & $8-9$ & 0.6335 & $9-13$ & 0.5933 & $10-18$ & 0.6821 & $12-18$ & 0.8629 & $16-17$ & 0.9977 \\
$6-18$ & 0.1325 & $8-10$ & 0.5051 & $9-14$ & 0.5621 & $11-12$ & 0.9340 & $13-14$ & 0.9474 & $16-18$ & 0.9909 \\
$7-8$ & 0.6378 & $8-11$ & 0.4275 & $9-15$ & 0.5451 & $11-13$ & 0.8794 & $13-15$ & 0.9186 & $17-18$ & 0.9932 \\
\hline
\end{tabular}

From Table 1, it can be seen that failure correlation coefficients from seventh floor to twelfth floor are larger than 0.7 and those of other floors are less than 0.7 under frequently occurred earthquakes. It indicates that failure from seventh floor to twelfth floor is statistically correlative and failure of other floors is statistically independent under frequently occurred earthquakes. Failure correlation sketch map of twelve-story frame shear-wall structure is shown in Figure 4.

From Table 2, it can be seen that failure correlation coefficients from tenth floor to eighteenth floor are lager than 0.7 and those of other floors are less than 0.7 under frequently occurred earthquakes. It indicates that failure from tenth floor to eighteenth floor is statistically correlative and failure of other floors is statistically independent under frequently occurred earthquakes. Failure correlation sketch map of eighteen-story frame shear-wall structure is shown in Figure 5.

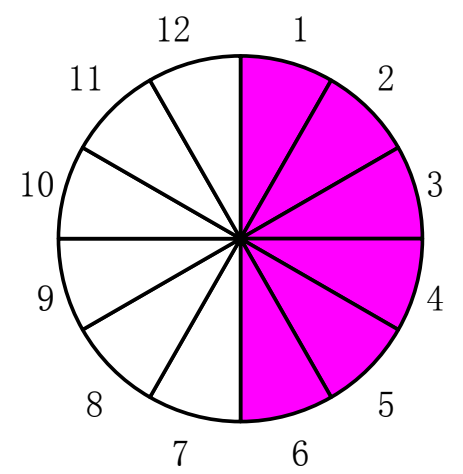

Figure 4. 12-story failure correlation sketch map 


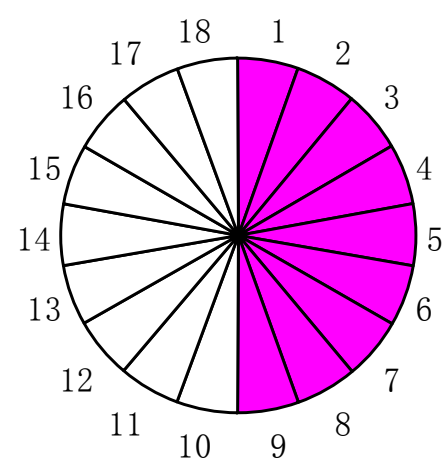

Figure 5. 18-story failure correlation sketch map

\subsection{Statistical Results of Interstory Drift}

In this paper, all interstory drifts are random variables. Interstory drifts statistical results of twelve-story frame shear-wall structure under frequently occurred earthquakes are shown in Figure 6, including maximum value, minimum value and mean value. Interstory drifts statistical results of eighteen-story frame shear-wall structure under frequently occurred earthquakes are shown in Figure 7, including maximum value, minimum value and mean value.

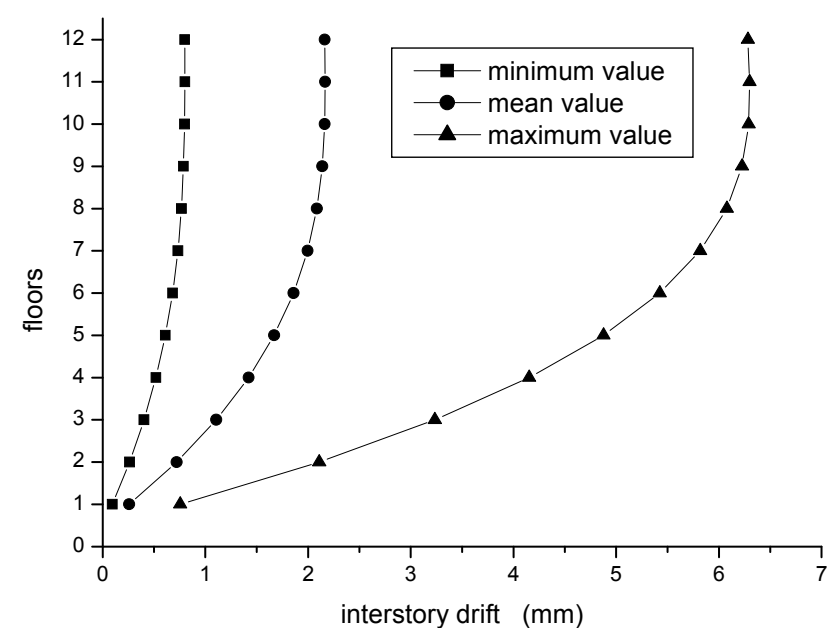

Figure 6. Statistical results of twelve-story interstory drift

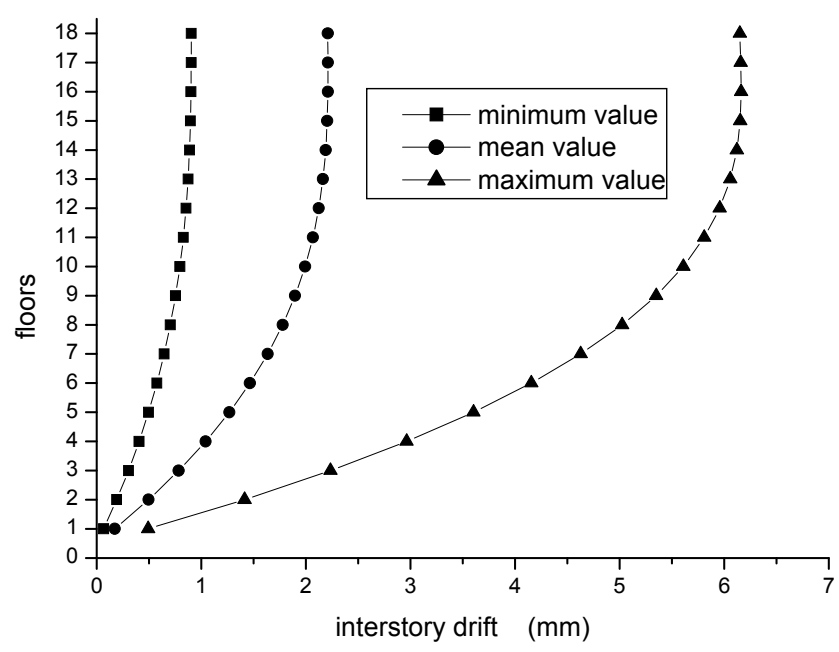

Figure 7. Statistical results of eighteen-story interstory drift 


\subsection{Main Failure Modes}

The main failure modes, failure probability, reliability index, representative failure models are separately shown in Table 3 and Table 4. Number in parentheses is failure floor and number outside parentheses is serial number in Table 3 and Table 4.

Table 3. Statistical results of twelve-story frame-shearwall structure

\begin{tabular}{cccc}
\hline Main failure modes & Failure probability & Reliability index & Representative failure modes \\
\hline $1(11)$ & 0.0227 & 2.0000 & $1(11)$ \\
$2(10)$ & 0.0220 & 2.0142 & \\
$3(12)$ & 0.0213 & 2.0276 & \\
$4(9)$ & 0.0203 & 2.0476 & \\
$5(8)$ & 0.0170 & 2.1200 & \\
$6(7)$ & 0.0128 & 2.2322 & \\
$7(6)$ & 0.0067 & 2.4730 & $2(6)$ \\
$8(5)$ & 0.0019 & 2.8943 & $3(5)$ \\
$9(4)$ & 0.0004 & 3.3528 & $4(4)$ \\
\hline
\end{tabular}

Table 4. Statistical results of eighteen-story frame-shearwall structure

\begin{tabular}{cccc}
\hline Main failure modes & Failure probability & Reliability index & Representative failure modes \\
\hline $1(16)$ & 0.0227 & 2.0000 & $1(16)$ \\
$2(17)$ & 0.0221 & 2.0123 & \\
$3(18)$ & 0.0218 & 2.0179 & \\
$4(15)$ & 0.0212 & 2.0296 & \\
$5(14)$ & 0.0206 & 2.0416 & \\
$6(13)$ & 0.0188 & 2.0791 & \\
$7(12)$ & 0.0167 & 2.1273 & \\
$8(11)$ & 0.0146 & 2.1808 & \\
$9(10)$ & 0.0105 & 2.3079 & $2(9)$ \\
$10(9)$ & 0.0067 & 2.4730 & $3(8)$ \\
$11(8)$ & 0.0027 & 2.7821 & $4(7)$ \\
$12(7)$ & 0.0011 & 3.0619 & $5(6)$ \\
$13(6)$ & 0.0004 & 3.3528 & \\
\hline
\end{tabular}

From Table 3, it can be seen that there are nine main failure modes and four representative failure modes for twelve-story frame shear-wall structure under frequently occurred earthquakes. From Table 4, it can be seen that there are thirteen main failure modes and five representative failure modes for eighteen-story frame shear-wall structure under frequently occurred earthquakes.

\subsection{Calculation of Structural System Reliability}

In this paper, structural system reliability is calculated according to the following methods respectively:

(1) Method 1: when the failure mode is completely independent, system reliability can be expressed as:

$$
P_{f}=1-\prod_{i=1}^{n}\left(1-P_{f i}\right)
$$

Where $P_{f i}$ is the failure probability of $i$-th failure modes, $n$ is the number of failure modes.

(2) Method 2: when the failure mode is fully relevant, system reliability can be expressed as: 


$$
P_{f}=\max P_{f i}
$$

(3) Method 3: Monte Carlo method

Monte Carlo method is considered to be an accurate method calculating system reliability. When Monte Carlo method is used, system reliability can be expressed as:

$$
P_{f}=\frac{n_{f}}{N}
$$

Where $n_{f}$ is the number of structural failure. $N$ is the total number of random simulations.

(4) Method 4: PNET method

Based on PNET method, structural system reliability can be expressed as:

$$
P_{f}=1-\prod_{i=1}^{m}\left(1-P_{f i}\right)
$$

Where $m$ is the number of representative failure modes. The calculation results of structural system reliability are shown in Table 5.

Table 5. Structural system reliability of frame shear-wall structures under frequently occurred earthquakes

\begin{tabular}{ccccc}
\hline \multirow{2}{*}{ Types } & \multicolumn{2}{c}{ Twelve-story frame shear-wall structure } & \multicolumn{2}{c}{ Eighteen-story frame shear-wall structure } \\
\cline { 2 - 5 } & Failure probability & Probability index & Failure probability & Probability index \\
\hline Method 1 & 0.1186 & 1.1820 & 0.1661 & 0.9700 \\
Method 2 & 0.0227 & 2.0000 & 0.0227 & 2.0000 \\
Method 3 & 0.0356 & 1.8042 & 0.0494 & 1.6507 \\
Method 4 & 0.0315 & 1.8592 & 0.0333 & 1.8343 \\
\hline
\end{tabular}

\section{Conclusions}

To sum up the above discussion, some conclusions can be drawn as follows. The failure between the layers of high-rise frame shear-wall structure is neither fully independent, nor entirely relevant under frequently occurred earthquakes. The failure relevant number accounts for half the total number of high-rise frame shear-wall structure. The failure relevant layers concentrate on the upper part of high-rise frame shear-wall structure. It is feasible to calculate structural system reliability considering the failure of interstory deformation as main failure modes, and the calculation of structural system reliability can be greatly simplified.

\section{Acknowledgment}

The author is grateful to the editor and a referee whose helpful comments improved the presentation. This work was supported by key projects of Office of Science and Technology of Henan Province (092102310247).

\section{References}

Ang, A. H-S., \& Ma, H-F. (1981). On the Reliability of Structural Systems. Proceedings of the 3rd International Conference on Structural Safety and Reliability. Trondheim, Norway, 295-314.

Ang, A. H-S., \& Tang, W. H. (1984). Probability Concepts in Engineering Planning and Design. Volume II: Decision, Risk, and Reliability, 504-506. New York: John Wiley \& Sons.

Cheng, G. D., \& Gang, L. (2000). Some key problems on performance-based seismic design. Journal of building structures, 21(1), 5-11 (In Chinese).

Chou, K. C., Mclntosh, C., \& Corotis, R. B. (1982-1983). Observations on structural system reliability and the role of modal correlations. Structural Safety, 189 1(3), http://dx.doi.org/10.1016/0167-4730(82)90025-X

Fosch, R. O., Li, H., \& Zhang, J. (2002). Reliability and performance-based design: a computational approach and applications. Structural Safety, 24(2-4), 205-218. http://dx.doi.org/10.1016/S0167-4730(02)00025-5

Li, G., \& Cheng, G. D. (2001). Reliability and performance based optimization design for seismic RC frame-wall 
structures. Chinese Journal of Computational Mechanics, 18(3), 67-71 (In Chinese).

Li, G., \& Cheng, G. D. (2002). Optimum decision of the target value of performance-based structural system reliability. Chinese Journal of Computational Mechanics, 19(2), 127-131 (In Chinese).

Möller, O., Foschi, Ricardo O., Rubinstein, M., \& Laura, Q. (2009). Seismic structural reliability using different nonlinear dynamic response surface approximations. Structural Safety, 31(5), $432-442$. http://dx.doi.org/10.1016/j.strusafe.2008.12.001

Moses, F. (1990). New directions and research needs in system reliability research. Structural Safety, 7(2-4), 93-100. http://dx.doi.org/10.1016/0167-4730(90)90059-X

Ou, J. P., \& Hou, G. L. (2001). Random pushover analysis method and its application in earthquake- resistant reliability evaluation of structural systems. Journal of building structures, 22(6), 81-86 (In Chinese). 